Mandrágoras, clínica psicanalítica: Freud e Winnicott

Sérgio Gouvêa Franco, Manoel Tosta Berlinck, Karin Hellen Kepler Wondracek São Paulo: Primavera Editorial, 2014, 180 págs.

\title{
Um psicanalista em seu tempo
}

\author{
Nelson da Silva Junior*1
}

Caso devesse escolher apenas uma palavra para apresentar o autor principal desse livro, ela seria a generosidade, a capacidade de partilha e doação ao outro sem espera de nada em troca. Os coautores deste livro, Manoel Berlinck e Karin Wondracek, seus amigos pessoais, certamente o conhecem bem e concordariam com esta pocket presentaton de Sérgio Franco. Ao leitor, gostaria de dizer que ele escreve tal como fala: Sérgio tem um pensamento vivaz, argumentação límpida, erudição surpreendente em áreas aparentemente excludentes, tudo isso movido por uma pulsação de afetos plena de humanidade. Note-se: humanidade, não humanismo, pois a primeira remete à humildade de reconhecer os limites do humano e à busca paciente por uma melhoria. $\mathrm{O}$ humanismo, por sua vez, aponta à exigência dos ideais. Resulta desta rara combinação um homem admirável, um psicanalista ímpar e um autor exemplar.

Mas vamos ao que interessa, ao livro ele mesmo. Grosso modo, ele se divide em duas partes, a primeira orientada pela

${ }^{* 1}$ Universidade de São Paulo - USP (São Paulo, SP, Br). 
obra de Freud, e a segunda, pela de Winnicott. Esta é, a meu ver, uma divisão ainda imprecisa, prefiro uma outra, que apresento a seguir. Para além de seu interesse didático, uma vez que cada tema abordado é devidamente contextualizado histórica e conceitualmente, os textos se sucedem em uma agradável harmonia entre os quatro eixos seguintes: 1. A história da psicanálise e o homem Freud - presente nos dois primeiros capítulos, voltados às relações de respeito mútuo e amizade entre Freud e o Pastor Pfister. 2. O cuidado e o tato clínico - presente em todo o livro, mas particularmente visível nos capítulos "O Caso Nancy: a dor saindo pela pele", "A transferência na histeria..." e no último capítulo do livro "O atendimento de pacientes difíceis". 3. Uma reflexão incansável sobre a antropologia filosófica oriunda da psicopatologia da psicanálise — em particular nos três primeiros capítulos dedicados a Winnicott e no capítulo "Uma leitura de recordar, repetir e elaborar", onde Sérgio isola uma dupla temporalidade, constitutiva do psiquismo, a partir da oposição entre a história e a repetição. E last, but not least, 4. um debate de extremo valor entre a clínica e a filosofia e, particularmente, com a epistemologia, graças a uma reflexão lúcida e séria no capítulo sobre "A realidade na neurose, na perversão e na psicose".

Não poderia deixar de mencionar nesta apresentação outra rara, mas valiosa qualidade de Sérgio: sua honestidade com as referências bibliográficas. Para além do que é mais comum entre nós, ou seja, a restrição das referências aos psicanalistas estrangeiros, encontramos na própria trama conceitual uma longa lista de referências nacionais: S. Alonso, Galende, M. Chnaiderman, J. Birman, R. Mezan, L.C. Figueiredo, F. Ferraz, H. Macedo, M. Rezende, I. Gerber, N. Coelho, D. Gurfinkel, Outeiral, F. F. Cesar, entre outros, figuram não só nas referências bibliográficas, bem educado costume, como também na construção dos argumentos. Sérgio demonstra assim a maturidade de um psicanalista em seu tempo, em intenso diálogo com seus pares.

Gostaria, para concluir este texto, cuja brevidade não deixará de cometer sérias injustiças ao livro, de fazer uma nota elogiosa à originalidade do segundo capítulo, onde Sérgio desdobra um interessantíssimo debate a respeito do lugar do erotismo na religião, e sua relação com a fantasia e a criatividade, ultrapassando os limites que em geral sentenciam a religião no pensamento dos psicanalistas. Aqui, uma leitura metapsicológica de extremo rigor demostra uma abertura num campo tenso, atravessado de preconceitos, mas onde Sérgio navega com extrema destreza e segurança, conduzindo seus passageiros pelo estreito de Sila e Caribdes sem pestanejar e fazendo avançar em algumas latitutes as fronteiras do pensamento psicanalítico. 


\section{RESENHA BIBLIOGRÁFICAS}

Citação/Citation: Silva Junior, N. (2015, março). Um psicanalista em seu tempo. Resenha do livro Mandrágoras, clínica psicanalitica: Freud e Winnicott. Revista Latinoamericana de Psicopatologia Fundamental, 18(1), 167-169.

Editor do artigo/Editor: Profa. Dra. Sonia Leite

Recebido/Received: 14.10.2014/ 10.14.2014 Aceito/Accepted: 19.12.2014 / 12.19.2014

Copyright: (C) 2009 Associação Universitária de Pesquisa em Psicopatologia Fundamental/ University Association for Research in Fundamental Psychopathology. Este é um artigo de livre acesso, que permite uso irrestrito, distribuição e reprodução em qualquer meio, desde que o autor e a fonte sejam citados / This is an open-access article, which permits unrestricted use, distribution, and reproduction in any medium, provided the original authors and sources are credited.

\section{Nelson da Silva Junior}

Psicanalista; Professor do Instituto de Psicologia da Universidade de São Paulo - USP (São Paulo, SP, Br); Membro do Departamento de Psicanálise do Instituto Sedes Sapientiae (São Paulo, SP, Br); Membro da Associação Universitária de Pesquisa em Psicopatologia Fundamental - AUPPF (São Paulo, SP, Br).

Al. Irae, 620/16

04075-000 São Paulo, SP, Br

e-mail: nesj@terra.com.br 